\title{
International Journal of Environmental Science and Technology Adsorption of diclofenac on activated carbon and its hypochlorination in the presence of dissolved organic matter --Manuscript Draft--
}

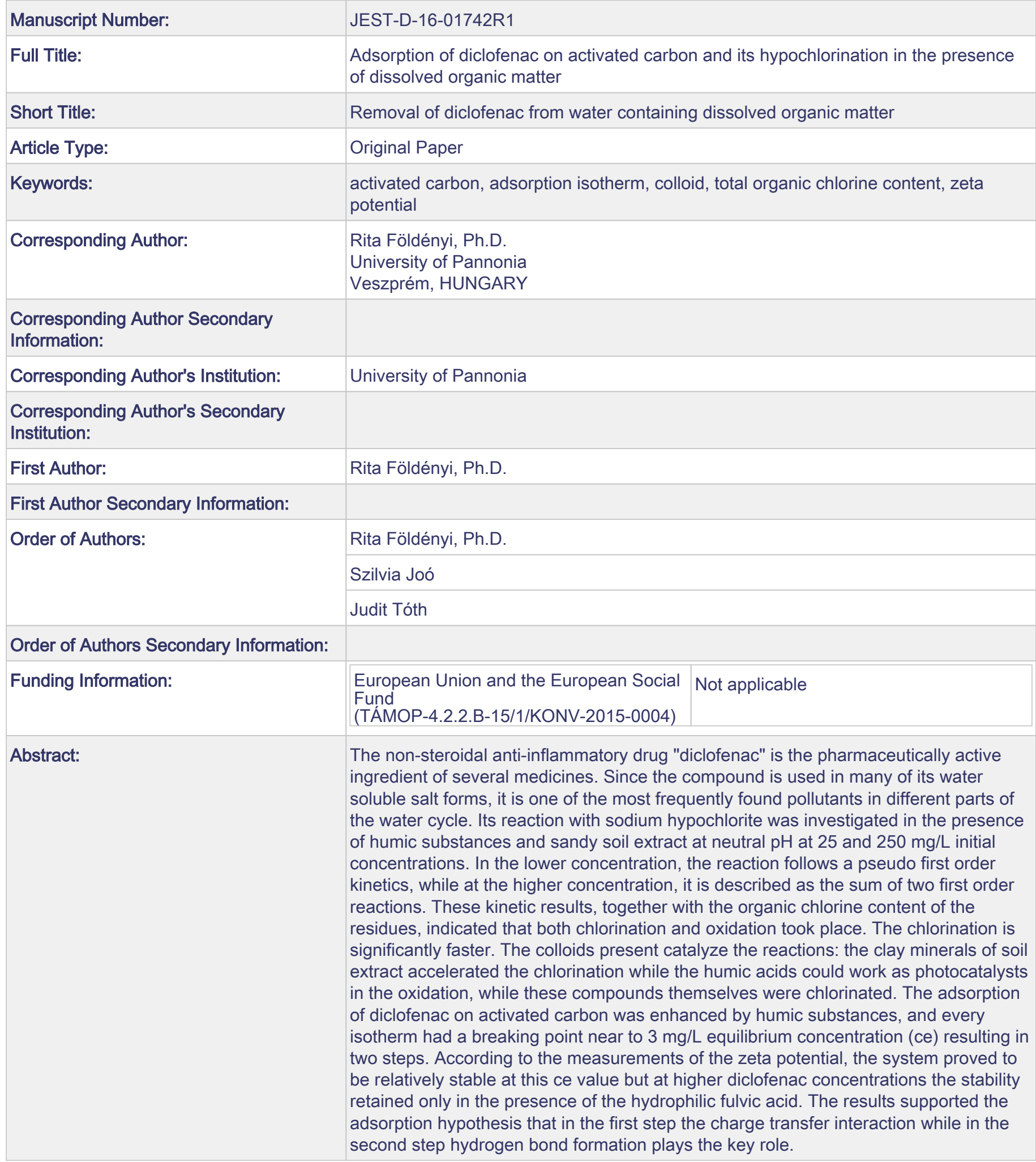


Adsorption of diclofenac on activated carbon and its hypochlorination in the presence of dissolved organic matter

Short title: Removal of diclofenac from water containing dissolved organic matter

$$
\text { R. Földényi }{ }^{1, *}, \text { Sz. Joó }{ }^{1,2}, \text { J. Tóth }{ }^{3}
$$

${ }^{1}$ Department of Earth and Environmental Sciences, University of Pannonia, 10 Egyetem Street, H-8200 Veszprém, Hungary

${ }^{2}$ Agricultural Institute, Centre for Agricultural Research, Hungarian Academy of Sciences, 2 Brunszvik Street, H-2462 Martonvásár, Hungary

${ }^{3}$ Institute of Materials and Environmental Chemistry, Research Centre for Natural Sciences, Hungarian Academy of Sciences, 2 Magyar tudósok Boulevard, H-1117 Budapest, Hungary

*Corresponding author:

Tel.: +3688624000/6052; E-mail address: foldenyi@almos.uni-pannon.hu (R. Földényi) 
Adsorption of diclofenac on activated carbon and its hypochlorination in the presence of dissolved organic matter

Short title: Removal of diclofenac from water containing dissolved organic matter

\begin{abstract}
The non-steroidal anti-inflammatory drug "diclofenac" is the pharmaceutically active ingredient of several medicines. Since the compound is used in many of its water soluble salt forms, it is one of the most frequently found pollutants in different parts of the water cycle. Its reaction with sodium hypochlorite was investigated in the presence of humic substances and sandy soil extract at neutral $\mathrm{pH}$ at 25 and $250 \mathrm{mg} / \mathrm{L}$ initial concentrations. In the lower concentration, the reaction follows a pseudo first order kinetics, while at the higher concentration, it is described as the sum of two first order reactions. These kinetic results, together with the organic chlorine content of the residues, indicated that both chlorination and oxidation took place. The chlorination is significantly faster. The colloids present catalyze the reactions: the clay minerals of soil extract accelerated the chlorination while the humic acids could work as photocatalysts in the oxidation, while these compounds themselves were chlorinated. The adsorption of diclofenac on activated carbon was enhanced by humic substances, and every isotherm had a breaking point near to $3 \mathrm{mg} / \mathrm{L}$ equilibrium concentration $\left(c_{e}\right)$ resulting in two steps. According to the measurements of the zeta potential, the system proved to be relatively stable at this $c_{e}$ value but at higher diclofenac concentrations the stability retained only in the presence of the hydrophilic fulvic acid. The results supported the adsorption hypothesis that in the first step the charge transfer interaction while in the second step hydrogen bond formation plays the key role.
\end{abstract}

Keywords: activated carbon, adsorption isotherm, colloid, total organic chlorine content, zeta potential 


\section{Introduction}

In surface and subsurface waters, pollution by pharmaceuticals occurs most frequently by the effluents of production plants or by the discharge of communal waste waters. According to the estimation of Zhang et. al. (2008), the worldwide consumption of the non-steroidal antiinflammatory drug diclofenac (2-(2,6-dichloranilino)phenylacetic acid, Fig. 1) amounts up to 940 tons per year. Since the compound may be used in any of its water soluble forms, it is one of the most frequently identified pollutants in different parts of water cycle including the groundwater and soil too (Heberer and Heberer, 2002). The highest concentration of diclofenac in the Danube River at Budapest (Hungary) was found to be $931 \mathrm{ng} / \mathrm{L}$ (Helenkár et. al., 2010). The most probable source of this contamination can be traced back to the inefficient treatment of the waste water. Efficiency of the removal of diclofenac from effluents was estimated at $21.8-28.5 \%$ due to its low adsorptive retention on the sludge particles of the sewage leading to a continuous pollution of the receiving water body (Ratola et. al., 2012). Most of the raw water in Hungary is produced by the so called bank filtration wells $(44 \%)$ which are fed principally by surface water sources like the Danube in Budapest. The efficient removal of diclofenac presents therefore a vital problem to the current environmental research concerned with the treatment of both raw waters and industrial effluents. Despite of the recent introduction of advanced oxidation processes for elimination of organic compounds (Vogna et. al., 2004; Giri et. al., 2010; 2011; Saleh and Gupta, 2011; 2012; Gupta et. al., 2012) chlorine, or as an alternative, sodium hypochlorite, still remained in use as disinfectant in most drinking water plants as a cost effective oxidant.

The incidence of diclofenac in the water of public pools and thermal bathes is highly probable since people use it not only as an oral but also as an external dermal medication (e.g. gel). The discharged effluents of these facilities contain therefore both the diclofenac and residues of the disinfectant.

Considering that the reactions between the chlorine and the dissolved organic components lead to carcinogenic products (Acero et. al., 2010) the implementation of chlorine calls therefore for extreme care and supervision. Compounds containing aromatic rings like diclofenac and humic substances (HS) in any types of water can be also chlorinated. Products formed in the reaction of diclofenac and chlorine, were identified as it is shown in Fig. 2. (Soufan et. al., 2012; Rigobello et. al., 2013).

Humic substances (HS) are ubiquitous in surface and subsurface waters and represent the major fraction of the dissolved organic matter (DOM). The two congener macromolecular colloid substances of the HS are the fulvic acids (FA) and the humic acids (HA). Their comparison highlights the following facts: fulvic acids are having lower molecular mass, relatively higher number of carboxylic groups, lower aromatic character and higher solubility in water which is almost independent of the $\mathrm{pH}$. On the contrary, humic acids are substances with higher molecular mass, containing fewer numbers of dissociable functional groups, higher aromatic character and low solubility in water that attains an appreciable value in alkaline media only (Janos, 2003). Due to the organic content of the sandy soil type of bank filter media, the raw water so produced inevitably contains some DOM, most of it identified as fulvic acids (Ertli et. al., 2004).

One of the applied methods for the removal of diclofenac is based on the oxidation with chlorine (DCF $+\mathrm{Cl}_{2} \rightarrow$ products). Decomposition reactions of organic pollutants in aquatic environment are liable to follow either zero or pseudo first order kinetics described by the simple rate equations: $-d c / d t=k$ and $-d c / d t=k \cdot c$, respectively (Wüst et. al., 1999; Schwarzenbach et. al., 1993). The pseudo first order approach is based upon the hypothesis that the concentration of oxidant hardly changes during the reaction because of its large excess as compared to the DCF. Consequently, in the rate equation its concentration raised to 
power zero. The usual integrated form of these rate equations are given by (Eq. 1.) and (Eq. the second case it can be calculated according to (Eq. 4.).

$$
\begin{gathered}
c(t)=c_{0}-k \cdot t \\
t_{1 / 2}=\frac{c_{0}}{2 \cdot k} \\
c(t)=c_{0} \cdot e^{-k \cdot t} \\
t_{1 / 2}=\frac{\ln 2}{k}=\frac{0.693}{k}
\end{gathered}
$$

where $c_{0}$ and $c(t)$ are the concentration of the DCF at the start of the process and at an arbitrary time $t, k$ is the zero or first order rate constant, $t_{1 / 2}$ is the half-life time.

In the reaction with chlorine, the kinetic order depends on the ratio of the reactants as well as on the experimental conditions ( $\mathrm{pH}$, temperature etc.).

In addition to the oxidation methods, adsorption is another important process considered for the removal of organic pollutants of water. For this purpose the most frequently used industrial adsorbent is the activated carbon (AC). Recent results proved that the efficiency of the removal by AC adsorption is less for hydrophilic than for hydrophobic compounds (Nam et. al., 2014). Experiments carried out with multi-walled carbon nanotubes (MWCNT) showed that not only the apolar but also the polar, ionic pollutants can be successfully eliminated by MWCNT in coated or composite forms (Gupta et. al., 2011; Saleh, 2011; Saleh et. al., 2011; Ai et. al., 2011; İlbay et. al., 2015). For different types of commercial activated carbons, the maximal adsorption capacity for diclofenac at $\mathrm{pH}=7.98$ was approximately $10^{-4}$ $\mathrm{mol} \mathrm{g}^{-1}$ (Rakić et. al., 2014). The efficacy of biomass-based AC at $\mathrm{pH}=5$ proved to be similar (Bernardo et. al., 2016). The experimental adsorption data are interpreted by using the Freundlich or Langmuir isotherm equations (Schwarzenbach et. al., 1993; Saleh and Gupta, 2014; Bernardo et. al., 2016). In the case of multi-step isotherms the equation (Eq. 5.) suggested by Czinkota et. al. (2002) can be used:

$$
q=\sum_{i=1}^{s}\left\{\frac{q_{T i} \cdot K_{i} \cdot\left(c-b_{i}+\left|c-b_{i}\right|\right)^{n_{i}}}{2^{n_{i}}+K_{i} \cdot\left(c-b_{i}+\left|c-b_{i}\right|\right)^{n_{i}}}\right\}
$$

where $s$ is the number of steps of the isotherm. Each step is characterized by the following parameters: adsorption capacity $\left(q_{T_{i}}\right)$, equilibrium constant $\left(K_{i}\right)$, critical concentration limit $\left(b_{i}\right)$ and the average degree of association $\left(n_{i}\right)$ assigned to the $i$ th step of the curve.

The molecular level interpretation of the adsorption is greatly aided by the measurement of the electrokinetic (zeta: $\zeta$ ) potential characterizing the surface electric charge developed on the sliding plane of the particle - solution interface. For practical purposes, approximately $|25|$ $\mathrm{mV}$ (Freitas and Müller, 1998) or eventually $|30| \mathrm{mV}$ value of the zeta potential is considered to be high enough to keep colloid particles in stable colloid solution and to avoid coagulation (Malvern, 2007; Xu et. al., 2007). Study of electrokinetic behavior of the activated carbon in different systems was the subject of several researchers (Xu et. al., 2007; Chingombe et. al., 2005; Dai, 1994; Anileak and Grzegorczuk-Nowacka, 2011). Without special pre-treatment (e.g. oxidation), electric charge of the carbon samples may change due to the amphoteric 
dissociation of the surface functional groups. After pre-oxidation of the $\mathrm{AC}$, the zeta potential $-\mathrm{pH}$ curves indicated a rapidly increasing negative surface charge between $\mathrm{pH} 1.5$ and 5 due to the dissociation of the surface carboxylic groups (Chingombe et. al., 2005). It was found that the higher is the $\mathrm{pH}$ of the system the lower is its zeta potential (Anileak and Grzegorczuk-Nowacka, 2011). The isoelectric point (IEP) of the carbon is shifted to higher $\mathrm{pH}$ values when the number of surface carboxylic groups is decreased (IEP represents the $\mathrm{pH}$ value where the zeta potential of the system is zero). The highest obtained IEP value was found at $\mathrm{pH}=7.8$ for a heat-treated AC sample where the treatment removed thoroughly the oxygen containing surface groups (Chingombe et. al., 2005). Negative sign of the zeta potential is also a symptom of defects in the conjugated $\pi$ electron system of the carbon surface functioning as a Lewis acid receiving electron pairs readily of molecules of the dispersing medium (Xu et. al., 2007).

The aim of our current research was to investigate the removal of the diclofenac, a pharmaceutically active ingredient of several medicines, by treatment of hypochlorite and also by adsorption methods under the conditions prevailing in natural waters. Special attention is paid to the role of the dissolved organic matter in these clean up processes. Model water samples are prepared containing diclofenac and different DOM components. Kinetic study of the transformation of diclofenac is carried out by using sodium hypochlorite. The mechanism of adsorption on activated carbon is studied by static equilibrium experiments accompanied by measurements of the zeta potential ensuing at the adsorbent solution interface.

\section{Materials and methods}

\section{Materials}

Sodium salt of the diclofenac (DCF, $\mathrm{Mw}=318 \mathrm{~g} / \mathrm{mol}$, purity $\geq 98 \%$ ) was purchased from Sigma Aldrich Co. Sodium humate (Roth+Co, Karlsruhe, Germany), fulvic acid (Organit Ltd., Hungary) and air dry sandy soil (Dabrony, Hungary) were used for preparation of DOM containing model systems. Composition of the soil: total organic carbon (TOC) $16 \mathrm{mg} \mathrm{C} / \mathrm{g}$ soil; main minerals: $9.9 \%$ albite, $3.6 \%$ chlorite, $4.8 \%$ mica, $3.8 \%$ microline, $55.3 \%$ quartz, $18.2 \%$ smectite. The granulated activated carbon (GAC) under the trade name FILTRASORB 400 (specific surface area is $1050 \mathrm{~m}^{2} / \mathrm{g}$ ) was provided by the firm Chemviron Carbon. Analytical grade $\mathrm{NaH}_{2} \mathrm{PO}_{4}, \mathrm{Na}_{2} \mathrm{HPO}_{4}, \mathrm{Na}_{2} \mathrm{~S}_{2} \mathrm{O}_{3}, \mathrm{Ca}\left(\mathrm{NO}_{3}\right)_{2}$ salts and potassium hydrogen phthalate standard were obtained from Reanal Chemical Co. (Hungary). The sodium hypochlorite solution was made by "Klorid" Chemical and Plastic Co. (Hungary). Its active chlorine content was determined by iodometric titration: $34.1 \mathrm{~g} \mathrm{Cl}_{2} / \mathrm{L}$. Acetonitril of HPLC grade was purchased from VWR, Hungary. The high-purity water was obtained from a Milli-Q water system (Millipore).

\section{Degradation of DCF in aqueous solutions}

Study of decomposition of DCF (initial concentration at $t_{0}: 250 \mathrm{mg} / \mathrm{L}=7.86 \cdot 10^{-4} \mathrm{~mol} / \mathrm{L}$ ) was investigated for 70 days in $30 \mathrm{~mL}$ of four different media: $0.01 \mathrm{~mol} / \mathrm{L} \mathrm{pH}=7$ phosphate buffer (Buffer); $0.1 \mathrm{~g} / \mathrm{L}$ fulvic acid solution (FASol) made by the Buffer (TOC: $27.7 \mathrm{mg} / \mathrm{L}$ ); $0.1 \mathrm{~g} / \mathrm{L}$ sodium humate solution (HASol) dissolved in the Buffer (TOC: $41.9 \mathrm{mg} / \mathrm{L}$ ); soil extract (SoilExtr). The latter was obtained by shaking $5 \mathrm{~g}$ soil with $50 \mathrm{~mL}$ Buffer for 1 hour then left to stand overnight, centrifuged at $1046 \mathrm{~g}$ for 30 minutes (Hettich Universal 32 centrifuge) then passed through filter paper (TOC: $46.7 \mathrm{mg} / \mathrm{L}$ ).

The process was followed by sampling the systems every seventh day and measuring the concentration of the DCF by high performance liquid chromatography (HPLC) detailed below. All samples were prepared in triplicate. 
For those samples containing no DCF, the TOC content was determined by Thermo Electron

\section{Static equilibrium measurements}

Adsorption isotherms were obtained by means of static equilibrium experiments using granulated activated carbon (GAC) adsorbent. DCF solutions (from 0 to $10 \mathrm{mg} / \mathrm{L}$, at eight different concentrations) were prepared by exact weighing and dissolved in different media: Buffer, FASol, HASol.

Exactly known amount of GAC (approx. $1 \mathrm{~g}$ ) was weighed into $500 \mathrm{~mL}$ glass stoppered conical flasks and $200 \mathrm{~mL}$ of the DCF solutions was added to each GAC sample. The flasks were then shaken for $30 \mathrm{~min}$ and left to stand 24 hours for equilibration at $25^{\circ} \mathrm{C}$. Equilibrium phases were filtered then analyzed by HPLC (all samples were in triplicate). The amount of adsorbed DCF was calculated from the equation:

$$
q=\frac{V \cdot\left(c_{0}-c_{e}\right)}{m}
$$

where $q$ is the amount of adsorbed DCF per unit mass of GAC $(\mathrm{mg} / \mathrm{g}), V$ is the volume of the equilibrium solution $(0.2 \mathrm{~L}), c_{0}$ and $c_{e}$ are the concentrations of the DCF $(\mathrm{mg} / \mathrm{L})$, before and after the equilibrium, respectively, $m$ is the weighed amount of $\mathrm{GAC}(\mathrm{g})$. In the equilibrium solutions, the zeta potential was measured (see below).

\section{HPLC conditions}

HPLC analyses were made by using a MERCK LaChrom HPLC system equipped with a LiChrospher 100 column filled with $5 \mu \mathrm{m}$ RP-18 packing material $(250 \mathrm{~mm} \times 4.6 \mathrm{~mm})$ and with a programmable UV detector $(\lambda=278 \mathrm{~nm}) .10 \mu \mathrm{L}$ samples were injected by an autosampler and eluted isocratically by using a hydro-organic eluent (acetonitrile $35 \%$, phosphate buffer $65 \%, 0.01 \mathrm{~mol} / \mathrm{L}, \mathrm{pH}=6.5$ ), flow rate: $1 \mathrm{~mL} \cdot \mathrm{min}^{-1}$. Calibration was made in the range of 0-250 $\mathrm{mg} \mathrm{DCF} / \mathrm{L}$. Retention time of DCF: $5.00 \mathrm{~min}$.

\section{TOX measurements}

In order to measure the organic chlorine content, first the inorganic chloride had to be removed. Samples were first mixed with $3 \mathrm{~mL} 10 \mathrm{~g} / \mathrm{L} \mathrm{Ca}\left(\mathrm{NO}_{3}\right)_{2}$ solution in order to precipitate the Ca-salt of the organics (DCF, HA, FA), then carefully evaporated, and washed with distilled water until the test with $\mathrm{AgNO}_{3}$ was negative for the chloride. The amount of the remaining insoluble $\mathrm{Ca}$-salts were dried and measured gravimetrically. 
TOX content of the dry samples was determined with Mitsubishi Chemical Model TOX-100 equipment working in solid as well as in liquid mode of operation. Equipment calibration was carried out by DCF solutions using the concentration range of $0-111 \mathrm{mg} \mathrm{Cl} / \mathrm{L}$.

\section{Determination of the electrokinetic (zeta: $\zeta)$ potential}

Zeta potential of the samples were determined by the ZetaSizer Nano ZS (Malvern) equipment. Measurements were made in different solutions: before adsorption experiments (Buffer, FASol, HASol) and after the adsorption experiments (Buffer_GAC, FASol_GAC, HASol_GAC). Measurements were carried out in a glass capillary cuvette at $25{ }^{\circ} \mathrm{C}$. Data were evaluated by the Smoluchowsky equation (Cieśla et. al., 2011). All measurements were carried out with three replicates.

\section{Results and discussion}

\section{Reaction of DCF with sodium hypochlorite}

For control investigation the decay of diclofenac was followed in different solutions as it is detailed above (see section "Materials and methods"). The degradation of DCF in the solutions can be described in every case by zero order kinetic (Eq. 1.) but it is negligible in the most solutions (Table 1). Just the application of soil extract resulted in a noteworthy reaction rate resulted in 87 days half-life time $\left(t_{1 / 2}\right)$ but this cannot disturb the results of experiments planned. Degradation can be catalyzed either by colloidal components (e.g. clay minerals) or by enzymes of microorganisms being present in the extract. Sodium humate accelerated slightly the decay $\left(t_{1 / 2}=567\right.$ day $)$ which might be caused by photocatalytic property of humic acid (Gerecke et. al., 2001; Földényi et. al., 2006, Lee et. al., 2014). Addition of sodium hypochlorite to the solutions was carried out in two different concentrations of DCF (25 and $250 \mathrm{mg} / \mathrm{L}$ ) in model systems detailed above (see section "Materials and methods").

The reaction using $25 \mathrm{mg} / \mathrm{L}$ initial concentration of DCF followed first order kinetic (Eq. 3, Table 2) and the compound disappeared practically within 30 min from every sample (Fig. 3.a.). The decay of DCF was the fastest in the soil extract just like it was found without $\mathrm{NaOCl}$. Since chlorine kills microorganisms and HS slightly influences the reaction rate, this indicates the catalytic role of other colloidal particles like clay minerals being present in the extract.

The decay of 10-times higher DCF initial concentration $(250 \mathrm{mg} / \mathrm{L})$ can be described by a function that has the sum of two first order kinetic equations (Rauch and Földényi, 2012) indicating two parallel chemical processes (Eq. 7., Table 3). According to the first part of the function the reaction is the fastest in the soil extract (see $k_{l}$ in Table 3) again but due to the second part the decay is slowing down here. Quenching the process after 2 hours the amount of remained DCF decreased in the solutions as follows: HASol > SoilExtr > FASol > Buffer (Fig. 3.b.). These results indicate that the decay is slower in the presence of humic substances which can be chlorinated, too. Therefore the chlorine is consumed and diclofenac will not be totally converted.

$$
c(t)=c_{1} \cdot e^{-k_{1} \cdot t}+c_{2} \cdot e^{-k_{2} \cdot t}
$$

where $c$ is the actual concentration at time $t, c_{1}$ and $c_{2}$ are the initial concentrations in the two parallel reactions (at $t=0, c=c_{1}+c_{2}$ ), $k_{1}$ and $k_{2}$ are the rate constants. The half-life time $\left(t_{i(1 / 2)}\right)$ was calculated for both steps $(i=1,2)$ by (Eq. 8.): 


$$
t_{i(1 / 2)}=\frac{\ln 2}{k_{i}}
$$

where $k_{i}$ is the rate constant for steps 1 and 2 .

Organic chlorine content of the residue after 2 hour-reaction using 0 and $250 \mathrm{mg} / \mathrm{L}$ initial concentration of DCF was determined by TOX equipment (Fig. 4.).

The results show that DCF is further chlorinated in the absence of DOM. Comparing to the decay curve (Fig. 3.b.) chlorination might be the first type of chemical processes (faster step) and the second type is the oxidation (slower step). This theory is supported by earlier identified products after chlorination reaction (Soufan et. al., 2012), (Fig. 2.) when the chlorine content of the compounds is always higher than the parent DCF molecule (except one product (2) formed in the second step of the consecutive reaction being hydrolysis (Rigobello et. al., 2013)). The chlorine content of these products and DCF was calculated and summarized in Table 4.

Despite the relatively high TOC value $(46.7 \mathrm{mg} / \mathrm{L})$ of the soil extract, it contains significantly less organic chlorine than the pure HASol when samples are compared in the absence of DCF (Fig. 4. Components alone, measured). This can be explained only by the special DOM composition of the extract which was less chlorinated than the different humic substances (FASol, HASol) or the diclofenac. When DCF and organic matter are together (Fig. 4. Components together, measured) in the model system the HA containing solution (TOC: 41.9 $\mathrm{mg} / \mathrm{L}$ ) had the lowest TOX value. This result (compared to the decay curve in Fig. 3.b.) also indicates that chlorination of DCF is the fastest process which cannot completely take place in the presence of HA. It was found only in the case of soil extract that the theoretical sum of DCF and DOM chlorination resulted in smaller TOX value (Fig. 4. Components together, summarized) than it was determined in the reality. This indicates again that chlorination of DCF is catalyzed in the soil extract having a special composition but this reaction cannot be completely finished since some organic components of the solution are also chlorinated and the active chlorine is consumed.

\section{Adsorption isotherms, zeta potential}

Fig. 5. shows the change of zeta potential as a function of concentrations for two sets of solutions. One set is represented by the initial solutions used for the static equilibrium experiments (Buffer, FASol, HASol). The other set of solutions is represented by the filtered equilibrated solutions (Buffer_GAC, FASol_GAC,HASol_GAC).

In all equilibrated solutions, the measured zeta values were lower in the absence of DCF $(c=$ $0 \mathrm{mg} / \mathrm{L}$ ) indicating a higher stability than the initial, non-equilibrated samples, for example zeta potential of the buffer alone was $-8.76 \mathrm{mV}$ that changed to $-19.2 \mathrm{mV}$ after equilibrium contact with GAC (concerning the measured zeta value of the buffer see our comment below). Earlier literature results for different activated carbon samples showed negative sign of the zeta potential at $\mathrm{pH} \geq 7$ established by the dissociation of the weakly acidic groups on the surface (Chingombe et. al., 2005; Dai, 1994; Anileak and Grzegorczuk-Nowacka, 2011). The presence of carboxylic as well as other oxygen containing functional groups (carbonyl, hydroxyl) on the surface of the AC adsorbent was proved by spectroscopy and computational evaluation (Al-Saadi et. al., 2013; Saleh et. al., 2014) as well as by Bohem's titration (Saleh, 2011).

Similarly to these literature findings, it can be assumed that the surface functional groups of GAC samples used in the present work are also weakly acidic types. When this system gets into contact with the dissolved HS (carrying dissociable carboxyl groups) the ensuing repulsive effect leads to a system of high stability. This effect can be observed most significantly when FA is present in the solution: zeta potential in the initial FA solution was - 
$30 \mathrm{mV}$ that changed dramatically to $-62.1 \mathrm{mV}$ after equilibration with the GAC (FASol_GAC).

Since the sodium salt of the diclofenac is highly soluble in water, the development of zeta potential, for this not particularly large molecule, is not expectable. Interestingly, however, its buffered solutions exhibit well reproducible negative zeta potential in the concentration range of $0-1 \mathrm{mg} / \mathrm{L}$ showing a minimum at $0.75 \mathrm{mg} / \mathrm{L}$ before GAC adsorption. In the current work, no effort was made to explain the origin of the zeta potential either in this, or in the above mentioned buffer systems but it was accepted as an experimental fact.

When HS are also present in the DCF solution, the measured zeta potentials are similar to each-other indicating that the two solutes are negatively charged under the given conditions and repel each-other resulting in a well stabilized (non-coagulating) system. Local drops in the value of the zeta potentials were observed in the HS-DCF system too at $0.75 \mathrm{mg} / \mathrm{L}$. In the presence of the GAC adsorbent, this local minimum of the curve tends to shift toward the lower concentrations indicating that the charge still remains negative but the actual charge density of the surface is reduced significantly due to the adsorption.

In Fig. 6. the obtained adsorption isotherms are presented for the GAC-DCF systems. The adsorption curves have two well-defined stages which become especially noteworthy in the presence of the HS macromolecules. This feature of the curve indicates the obvious role of the HS in the adsorption mechanism of the DCF which are in competition for the binding sites of GAC particularly at the investigated neutral $\mathrm{pH}$. This experimental condition was principally selected to demonstrate the effect of humic substances on the adsorption of DCF. There are, however, literature indications (Saleh and Gupta, 2014; Saleh et. al., 2014; İlbay et. al., 2015) that lower $\mathrm{pH}$ favors the adsorption of anionic pollutants on certain carbonaceous surfaces. For the studied systems acidic $\mathrm{pH}$ cannot be applied due to the poor solubility of HS. Looking upon the isotherms and on the values of the measured zeta potentials, it can be concluded in all cases, that the system proves to be more stable near to $3 \mathrm{mg} / \mathrm{L}$ equilibrium concentration $\left(c_{e}\right)$, which, in fact, is the concentration of the breaking point of the adsorption curve. At higher DCF concentrations, this relative stability is retained in the presence of FA only. The breaking point of the isotherm represents the so-called limiting value of the DCF concentration where the second step of the isotherm occurs or any other type of change that trigger alteration in the stability of the system (Czinkota et. al., 2002). It can be pointed out that in the presence of FA and HA the adsorption isotherms of the DCF (Fig. 6.) are similar but their equilibrium solution phases have different stability, FA is more stable than HA, (Fig. 5.) that is related to the different physico-chemical properties of these humic substances. In the HASol_GAC equilibrium solution the measured zeta potentials are becoming less negative than in the initial solution. This is the only system where the stability decreased after adsorption. It is caused by the competition between the humate and the DCF molecules for the binding sites of the GAC which are partly occupied by HA therefore the colloidal solution contains less negatively charged particles and the repulsive forces between the solutes would be reduced. This process is supported by our earlier results when the adsorption of HS was investigated on GAC (Joó and Földényi, 2012). When the equilibrium concentration exceeds $6.0 \mathrm{mg} / \mathrm{L}$, the GAC adsorbs more $\mathrm{HA}$ than $\mathrm{FA}$ at $\mathrm{pH}=7$. This is related to the more hydrophobic character of the HA.

Due to operation of repulsive forces between the acidic groups of the DCF and the GAC the adsorption is controlled by certain types of non-covalent interactions e.g. $\pi-\pi$ interaction or hydrogen bonding. Charge transfer can take place between the aromatic groups of diclofenac molecule and the graphene planes of the carbon surface behaving as a Lewis acid - base system. This is in agreement with the conclusions of Xu et. al. (2007) suggesting that negative sign of the zeta potential is an indication of the presence of Lewis acid sites on the surface of the GAC. Computational molecular orbital calculation for the adsorption of methyl orange 
(MO) on carbonaceous adsorbent (CA) suggested also the existence of $\pi-\pi$ interaction between the CA and the MO molecules (Saleh et. al., 2014). Results indicated that electron donation took place from the $\mathrm{SO}_{3}$ moiety of the $\mathrm{MO}$ rather than the benzene rings. Referring to our systems, this hypothesis predicts that the GAC is receiving electrons from the dissolved molecules DCF and HS. The formation of the second step on the isotherm (Fig. 6.) can be interpreted in terms of hydrogen bonding between the oxygen and nitrogen containing functionalities of the HS already adsorbed, and the secondary amino group of diclofenac.

\section{Conclusion}

Degradation of the diclofenac in aqueous solution is significant only in the soil extract indicating the catalytic activity of the clay minerals or eventually the enzymes of microorganisms.

In the presence of humic substances, the rate of the DCF - hypochlorite reaction is slowed down due to the chlorination of both the HS and DCF (diclofenac is chlorinated and also oxidized but the oxidation is a very slow process).

Photocatalytic effect of humic acid in the oxidation step can be supposed because the least amount of chlorinated products was detected when it was present in the system.

The catalytic effect of colloidal components (e.g. clay minerals) is supported both by the decay curve of DCF and by the TOX data of the reaction residue.

Adsorption of DCF on GAC was enhanced by the presence of HS already bound to the surface. The adsorbed amounts is increased further when the FA was introduced into the system contributing also to the stability of the equilibrium colloid solution. The mechanism of adsorption of DCF on the GAC is interpreted by non-covalent interactions involving the transfer of $\pi$ electrons between the Lewis acid carbon and the DCF.

Solute molecules (either the DCF or HS) adsorbed by the GAC are forming a new layer on the surface allowing further binding of DCF showing up as a second step on the isotherm. In this case, the formation of hydrogen bonds has a key role in the adsorption.

Our experiments indicated clearly that the presence of humic substances and other colloids too (e.g. clay minerals), has a strong impact on efficiency of the removal of DCF from any type of water (natural- and wastewater).

In the present work one type of commercial GAC was investigated. In order to make a comparison to the activity of the different materials, experiments presented above should be carried out with those adsorbents exactly under the same conditions as were applied here. Since drinking water as well as effluents of bathing resorts contains remaining active chlorine, the formation of chlorinated DCF and DOM has to be prevented. This is aided partly by the proper choice of adsorbent, by the knowledge of the isotherms accompanied by the measurements of the zeta potential of the equilibrium solution.

\section{Acknowledgements}

The activities and results of this study are part of the project TÁMOP-4.2.2.B-15/1/KONV2015-0004. The project is co-financed by the European Union and the European Social Fund.

\section{References}


Acero JL, Benitez FJ, Real FJ, Roldan G (2010) Kinetics of aqueous chlorination of some doi:10.1016/j.watres.2010.05.012

Ai L, Zhang C, Liao F, Wang Y, Li M, Meng L, Jiang J (2011) Removal of methylene blue from aqueous solution with magnetite loaded multi-wall carbon nanotube: kinetic, isotherm and mechanism analysis. J Hazard Mater 198:282-290

Al-saadi AA, Saleh TA, Kumar V (2013) Spectroscopic and computational evaluation of cadmium adsorption using activated carbon produced from rubber tires. J Mol Liq 188:136142. doi:10.1016/j.molliq.2013.09.036

Anileak MA, Grzegorczuk-Nowacka M (2011) Significance of zeta potential in the adsorption of fulvic acid on aluminium oxide and activated carbon. Pol J Environ Stud 20:1381-1386 Bernardo M, Rodrigues S, Lapa N, Matos I, Lemos F, Batista MKS, Carvalho AP, Fonseca I (2016) High efficacy on diclofenac removal by activated carbon produced from potato peel waste. Int J Environ Sci Technol 13:1989-2000. doi:10.1007/s13762-016-1030-3

Chingombe P, Saha B, Wakeman RJ (2005) Surface modification and characterisation of a coal-based activated carbon. Carbon 43:3132-3143. doi:10.1016/j.carbon.2005.06.021 Cieśla J, Bieganowski A, Janczarek M, Urbanik-Sypniewska T (2011) Determination of the electrokinetic potential of Rhizobium leguminosarum bv trifolii Rt24.2 using Laser Doppler Velocimetry - A methodological study. J Microbiol Meth 85:199-205

Czinkota I, Földényi R, Lengyel Z, Marton A (2002) Adsorption of propisochlor on soils and soil components equation for multi-step isotherms. Chemosphere 48:725-731. doi:10.1016/S0045-6535(02)00139-X

Dai M (1994) The effect of zeta potential of activated carbon on the adsorption of dyes from aqueous solution. I. The adsorption of cationic dyes: methyl green and methyl violet. J Colloid Interf Sci 164:223-228

Ertli T, Marton A, Földényi R (2004) Effect of pH and the role of organic matter in the adsorption of isoproturon on soils. Chemosphere 57:771-779.

doi:10.1016/j.chemosphere.2004.07.009

Földényi R, Ravasz B, Érsek Cs, Ertli T (2006) How do humic substances contribute to the degradation of tribenuron methyl and isoproturon in soil? In: Frimmel FH, Abbt-Braun G (eds.) Proc. of the 13th Meeting of the International Humic Substances Society, Band 45-II. Universität Karlsruhe (TH), Germany, pp. 849-852

Freitas C, Müller RH (1998) Effect of light and temperature on zeta potential and physical stability in solid lipid nanoparticle (SLN ${ }^{\mathrm{TM}}$ ) dispersions. Int J Pharm 168:221-229 Gerecke AC, Canonica S, Müller SR, Schärer M, Schwarzenbach RP (2001) Quantification of dissolved natural organic matter (DOM) mediated phototransformation of phenylurea herbicides in lakes. Environ Sci Technol 35:3915-3923

Giri RR, Ozaki H, Ota S, Takanami R, Taniguchi S (2010) Degradation of common pharmaceuticals and personal care products in mixed solutions by advanced oxidation techniques. Int J Environ Sci Technol 7:251-260

Giri RR, Ozaki H, Takayanagi Y, Taniguchi S, Takanami R (2011) Efficacy of ultraviolet radiation and hydrogen peroxide oxidation to eliminate large number of pharmaceutical compounds in mixed solution. Int J Environ Sci Technol 8:19-30 Gupta VK, Agarwal S, Saleh TA (2011) Synthesis and characterization of alumina-coated carbon nanotubes and their application for lead removal. J Hazard Mater 185:17-23. doi:10.1016/j.jhazmat.2010.08.053 Gupta VK, Jain R, Mittal A, Saleh TA, Nayak A, Agarwal S, Sikarwar S (2012) Photocatalytic degradation of toxic dye amaranth on $\mathrm{TiO}_{2} / \mathrm{UV}$ in aqueous suspensions. Mat Sci Eng C-Mater 32:12-17. doi:10.1016/j.msec.2011.08.018 
Heberer T, Heberer T (2002) Occurrence, fate, and removal of pharmaceutical residues in the aquatic environment: a review of recent research data. Toxicol Lett 131:5-17.

doi:10.1016/S0378-4274(02)00041-3

Helenkár A, Sebők Á, Záray Gy, Molnár-Perl I, Vasanits-Zsigrai A (2010) The role of the acquisition methods in the analysis of the non-steroidal anti-inflammatory drugs in Danube River by gas chromatography - mass spectrometry. Talanta 82:600-607.

doi:10.1016/j.talanta.2010.05.014

İlbay Z, Şahin S, Kerkez Ö, Bayazit ŞS (2015) Isolation of naproxen from wastewater using carbon-based magnetic adsorbents. Int J Environ Sci Technol 12:3541-3550.

doi:10.1007/s13762-015-0775-4

Janos P (2003) Separation methods in the chemistry of humic substances. J Chromatogr A 983:1-18

Joó Sz, Földényi R (2012) Removal of dissolved organic matter (DOM) from water with activated carbon and effective microorganisms. Water Supply 12:65-70

Lee E, Kyong H, Cho J (2014) Role of wetland organic matters as photosensitizer for degradation of micropollutants and metabolites. J Hazard Mater 276:1-9

Malvern Instruments (2007) Sample Dispersion and Refractive Index Guide. MAN0396 1.0, Malvern Instruments Ltd., Malvern, UK

Nam SW, Choi DJ, Kim, SK, Her N, Zoh KD (2014) Adsorption characteristics of selected hydrophilic and hydrophobic micropollutants in water using activated carbon. J Hazard Mater 270:144-52. doi:10.1016/j.jhazmat.2014.01.037

Rakić V, Rac V, Krmar M, Otman O, Auroux A (2014) The adsorption of pharmaceutically active compounds from aqueous solutions onto activated carbons. J Hazard Mater 282:141149. doi:10.1016/j.jhazmat.2014.04.062

Ratola N, Cincinelli A, Alves A, Katsoyiannis A (2012) Occurrence of organic microcontaminants in the wastewater treatment process. A mini review. J Hazard Mater 240:1-18

Rauch R, Földényi R (2012) The effect of alginite on the decomposition of the herbicide propisochlor. J Environ Sci Heal - Part B Pestic Food Contam Agric Wastes 47:670-676. doi:10.1080/03601234.2012.669212

Rigobello ES, Dantas ADB, Di Bernardo L, Vieira EM (2013) Removal of diclofenac by conventional drinking water treatment processes and granular activated carbon filtration. Chemosphere 92:184-191. doi:10.1016/j.chemosphere.2013.03.010

Saleh TA (2011) The influence of treatment temperature on the acidity of MWCNT oxidized by $\mathrm{HNO}_{3}$ or a mixture of $\mathrm{HNO}_{3} / \mathrm{H}_{2} \mathrm{SO}_{4}$. Appl Surf Sci 257:7746-7751.

doi:10.1016/j.apsusc.2011.04.020

Saleh TA, Agarwal S, Gupta VK (2011) Synthesis of MWCNT/MnO 2 and their application for simultaneous oxidation of arsenite and sorption of arsenate. Appl Catal B-Environ 106:46-53. doi:10.1016/j.apcatb.2011.05.003

Saleh TA, Al-saadi AA, Kumar V (2014) Carbonaceous adsorbent prepared from waste tires: Experimental and computational evaluations of organic dye methyl orange. J Mol Liq 191:8591. doi:10.1016/j.molliq.2013.11.028

Saleh TA, Gupta VK (2011) Functionalization of tungsten oxide into MWCNT and its application for sunlight-induced degradation of rhodamine B. J Colloid Interface Sci 362:337344. doi:10.1016/j.jcis.2011.06.081

Saleh TA, Gupta VK (2012) Photo-catalyzed degradation of hazardous dye methyl orange by use of a composite catalyst consisting of multi-walled carbon nanotubes and titanium dioxide. J Colloid Interface Sci 371:101-106. doi:10.1016/j.jcis.2011.12.038 
Saleh TA, Gupta VK (2014) Processing methods, characteristics and adsorption behavior of tires derived carbons: A Review. Adv Colloid Interface Sci 211:93-101.

doi:10.1016/j.cis.2014.06.006

Schwarzenbach RP, Gschwend EP, Imboden MD (1993) Environmental Organic Chemistry, John Wiley \& Sons, Inc. New York

Soufan M, Deborde M, Legube B (2012) Aqueous chlorination of diclofenac: Kinetic study and transformation products identification. Water Res 46:3377-3386.

doi:10.1016/j.watres.2012.03.056

Vogna D, Marotta R, Napolitano A, Andreozzi R, D'Ischia M (2004) Advanced oxidation of the pharmaceutical drug diclofenac with $\mathrm{UV} / \mathrm{H}_{2} \mathrm{O}_{2}$ and ozone. Water Res 38:414-422.

doi:10.1016/j.watres.2003.09.028

Wüst WF, Köber R, Schlicker O, Dahmke A (1999) Combined zero- and first-order kinetic model of the degradation of TCE and cis-DCE with commercial iron. Environ Sci Technol 33:4304-4309

Xu R, Wu C, Xu H (2007) Particle size and zeta potential of carbon black in liquid media. Carbon 45:2806-2809. doi:10.1016/j.carbon.2007.09.010

Zhang Y, Geißen SU, Gal C (2008) Carbamazepine and diclofenac: Removal in wastewater treatment plants and occurrence in water bodies. Chemosphere 73:1151-1161.

doi:10.1016/j.chemosphere.2008.07.086 


\section{Figure captions}

Fig. 1 Structural formula of the diclofenac

Fig. 2 Products identified in the reaction of diclofenac with chlorine

Fig. 3 Concentration decay of diclofenac in different model systems during treatment with hypochlorite at $\mathrm{pH}=7:$ a. $c_{0}(\mathrm{DCF})=25 \mathrm{mg} / \mathrm{L} ; \mathrm{b} . c_{0}(\mathrm{DCF})=250 \mathrm{mg} / \mathrm{L}$

Fig. 4 TOX data of the chlorinated solutions treated in the absence as well as in the presence of DCF

Fig. 5 Change of electrokinetic potential ( $\zeta$ ) versus concentration of DCF before (dotted curve) and after GAC (continuous curve) treatment

Fig. 6 Adsorption of DCF on GAC from different model solutions 
Table 1 Calculated parameters of the degradation reaction of DCF $\left(c_{0}=250 \mathrm{mg} / \mathrm{L}\right)$ at $\mathrm{pH}=7$ in different model systems

\begin{tabular}{ccccc}
\hline \multirow{2}{*}{ Parameter } & \multicolumn{4}{c}{ System } \\
\cline { 2 - 5 } & Buffer & FASol & HASol & SoilExtr \\
\hline$k(m g /$ L.day $)$ & 0.113 & 0.119 & 0.237 & 1.54 \\
$t_{1 / 2}($ day $)$ & 1183 & 1125 & 567 & 87 \\
$R^{2}$ & 1.0000 & 1.0000 & 0.9999 & 0.9998 \\
\hline
\end{tabular}


Table 2 Calculated parameters of the decay of DCF in different model systems during treatment with hypochlorite at $\mathrm{pH}=7, c_{0}(\mathrm{DCF})=25 \mathrm{mg} / \mathrm{L}$

\begin{tabular}{ccccc}
\hline \multirow{2}{*}{ Parameter } & \multicolumn{4}{c}{ System } \\
\cline { 2 - 5 } & Buffer & FASol & HASol & SoilExtr \\
\hline$k\left(s^{-1}\right)$ & 0.00453 & 0.00515 & 0.00458 & 0.00741 \\
$t_{1 / 2}(s)$ & 153 & 135 & 151 & 93.5 \\
$R^{2}$ & 0.9974 & 0.9970 & 0.9972 & 0.9991 \\
\hline
\end{tabular}


Table 3 Calculated parameters of the decay of DCF in different model systems during treatment with hypochlorite at $\mathrm{pH}=7, c_{0}(\mathrm{DCF})=250 \mathrm{mg} / \mathrm{L}$

\begin{tabular}{ccccc}
\hline \multirow{2}{*}{ Parameter } & \multicolumn{4}{c}{ System } \\
\cline { 2 - 5 } & Buffer & FASol & HASol & SoilExtr \\
\hline$c_{1}(\mathrm{mg} / \mathrm{l})$ & 205 & 175 & 153 & 155 \\
$k_{1}\left(\mathrm{~min}^{-1}\right)$ & 0.170 & 0.195 & 0.239 & 0.488 \\
$t_{1(1 / 2)}(\mathrm{min})$ & 4.08 & 3.56 & 2.90 & 1.42 \\
$c_{2}\left(\mathrm{mg}^{\prime}\right)$ & 41.5 & 71.7 & 93.4 & 86.0 \\
$k_{2}\left(\mathrm{~min}^{-1}\right)$ & 0.00115 & 0.00005 & 0.00005 & 0.00005 \\
$t_{2(1 / 2)}\left(\mathrm{min}^{\prime}\right)$ & 603 & 13863 & 13863 & 13863 \\
$R^{2}$ & 0.9998 & 1.0000 & 1.0000 & 0.9999 \\
\hline
\end{tabular}


Table 4 Chlorine content of diclofenac (Fig. 1.) and its derivatives (Fig. 2.) identified after

\begin{tabular}{cc}
\multicolumn{2}{c}{ chlorination } \\
\hline Symbol & $\mathrm{Cl}, \%$ \\
\hline $\mathbf{1}$ & 24.0 \\
$\mathbf{2}$ & 32.2 \\
$\mathbf{3}$ & 22.8 \\
$\mathbf{4}$ & 35.2 \\
$\mathbf{5}$ & 26.5 \\
$\mathbf{6}$ & 25.4 \\
$\mathbf{7}$ & 35.2 \\
\end{tabular}


Figure1<smiles>O=C(O)Cc1ccccc1Nc1c(Cl)cccc1Cl</smiles> 
<smiles>O=C(O)Cc1ccccc1Nc1c(Cl)cccc1Cl</smiles>

1<smiles>Cc1ccccc1Nc1c(Cl)cc(O)cc1Cl</smiles>

3<smiles>OCc1ccccc1Nc1c(Cl)cccc1Cl</smiles>

4<smiles>OCc1ccccc1Nc1c(Cl)cccc1Cl</smiles>

6<smiles>O=C(O)Cc1ccccc1Nc1c(O)cccc1Cl</smiles>

2<smiles>O=C1C=CC(=Nc2c(Cl)cccc2Cl)C(CO)=C1</smiles>

5<smiles>O=Cc1cc(O)ccc1Nc1c(Cl)cccc1Cl</smiles>

7 


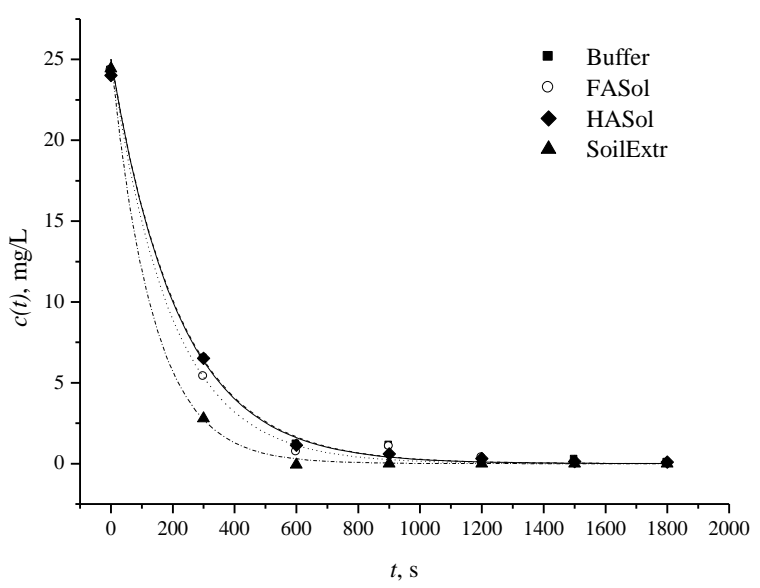

a.

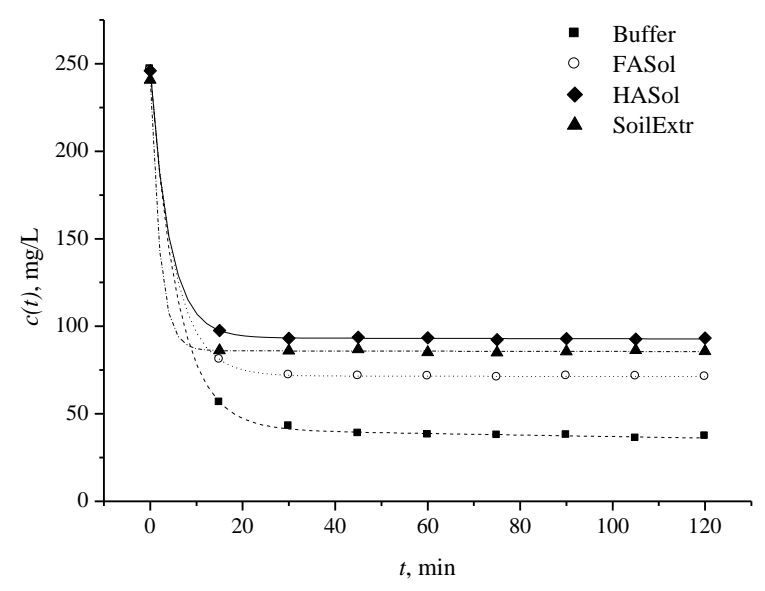

b. 


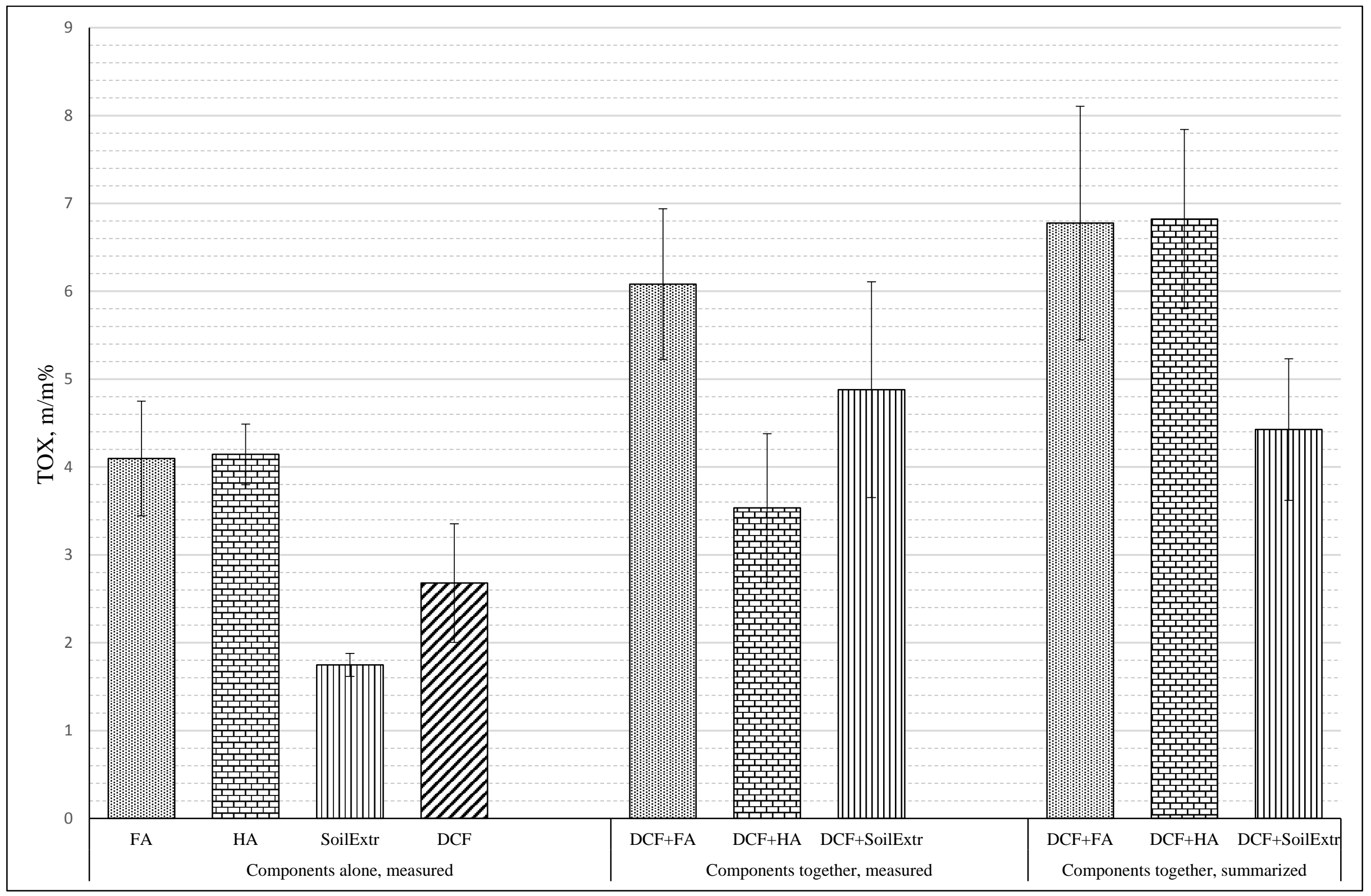




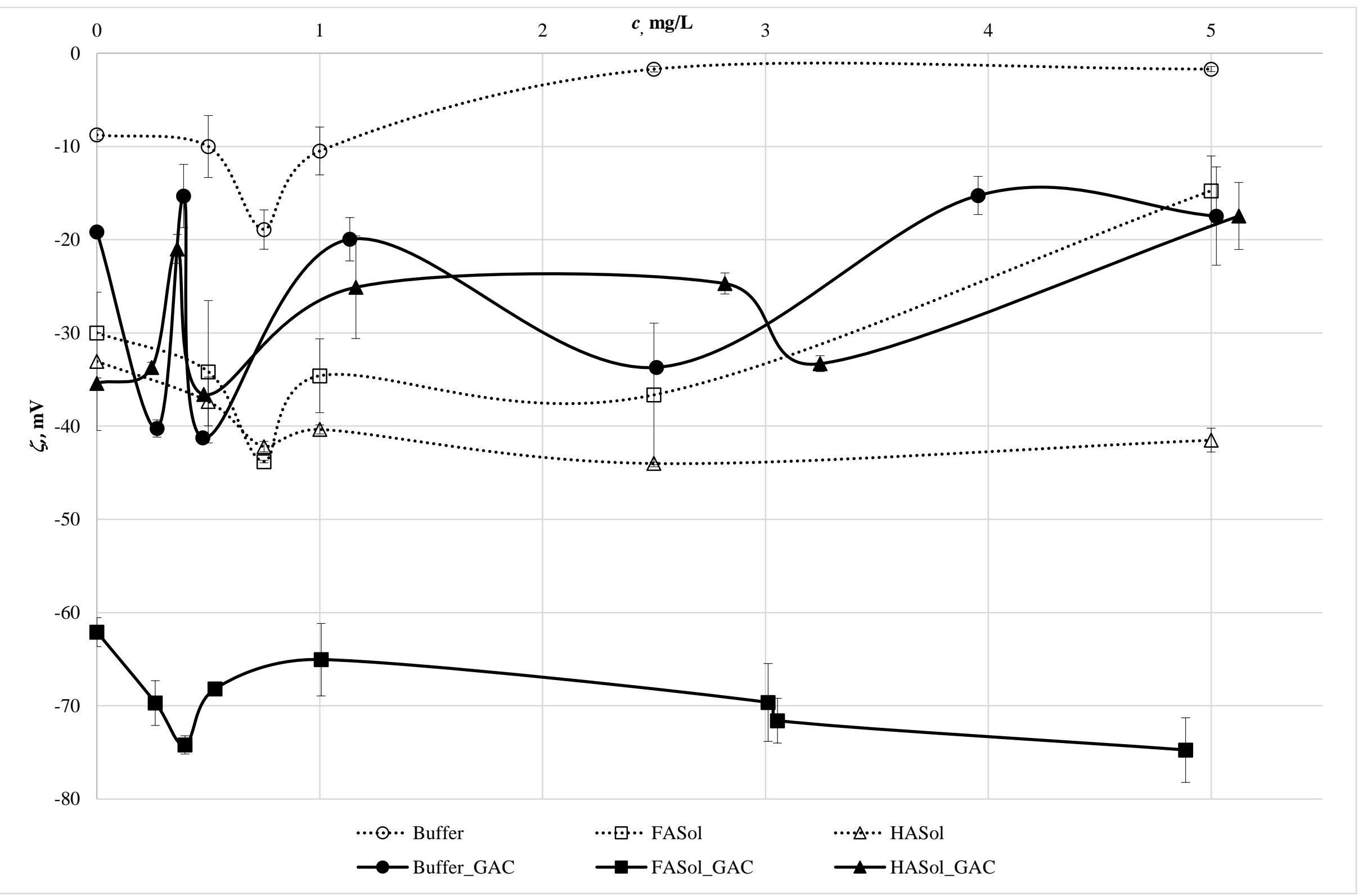




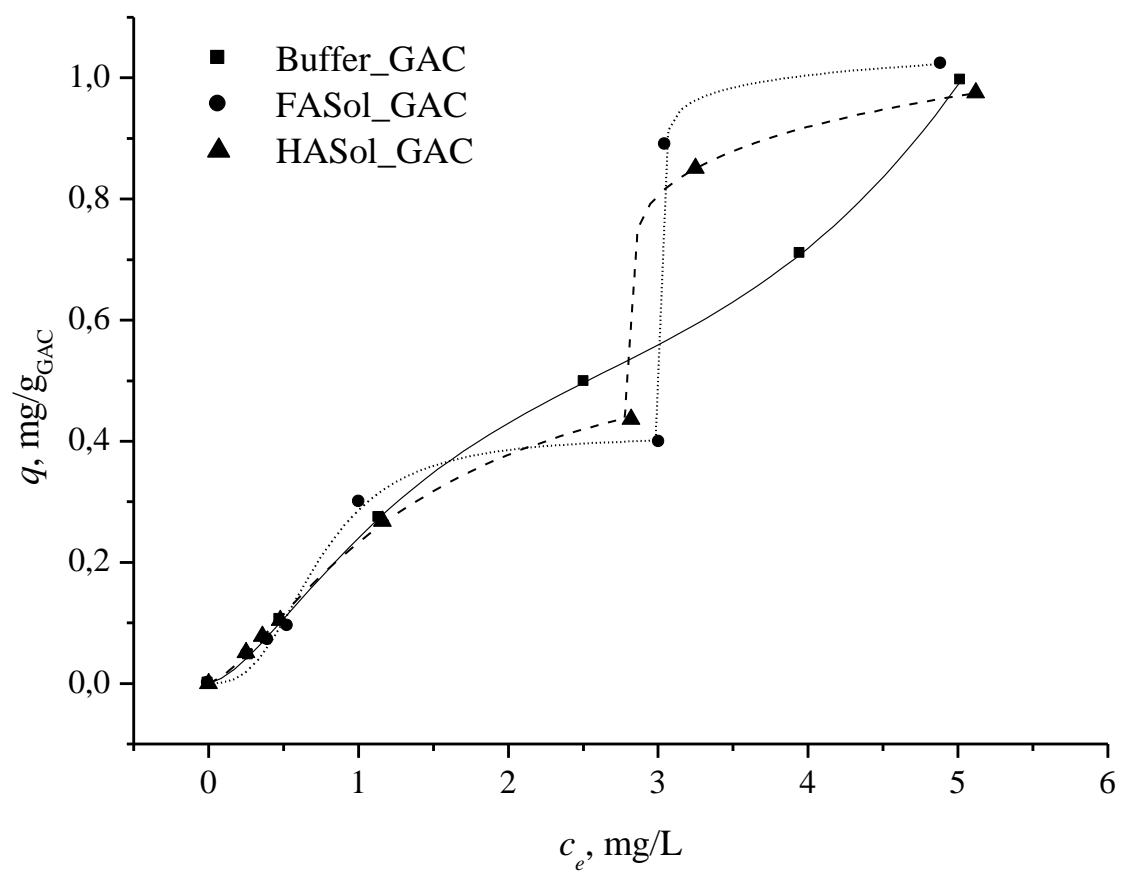

